\title{
Multiple Sclerosis: Oligoclonal IgG Bands, Prevalence, Prognosis and Effect of Latitude
}

\author{
Margarida Lopes ${ }^{1}$, João Paulo Figueiredo ${ }^{2}$ and Ana Valado ${ }^{1 *}$ \\ ${ }^{1}$ Polytechnic Institute of Coimbra, ESTeSC - Coimbra Health School, Biomedical Laboratory Sciences Department, Coimbra, \\ Portugal \\ ${ }^{2}$ Polytechnic Institute of Coimbra, ESTeSC - Coimbra Health School, Complementary Sciences Department, Coimbra, Portugal \\ *Corresponding author: Ana Valado, Polytechnic Institute of Coimbra, ESTeSC - Coimbra Health School, Biomedical Laboratory \\ Sciences Department, Coimbra, Portugal
}

ARTICLE INFO

Received: 幽 May 21, 2020

Published: 幽 June 09, 2020

Citation: Margarida Lopes, João Paulo Figueiredo, Ana Valado. Multiple Sclerosis: Oligoclonal IgG Bands, Prevalence, Prognosis and Effect of Latitude. Biomed J Sci \& Tech Res 28(2)-2020. BJSTR. MS.ID.004611.

Abbreviation: MS: Multiple Sclerosis; OCB IgG: Oligoclonal IgG Bands; CIS: Clinically Isolated Syndrome; RRMS: Relapsing Remitting MS; SPMS: Secondary Progressive MS; PPMS: Primary Progressive MS; CSF: Cerebrospinal Fluid; EDSS: Expanded Disability Status Scale
ABSTRACT

Multiple sclerosis (MS) is an inflammatory chronic disorder. It manifests itself by an inflammation of the central nervous system and by a deregulation of the immune system, leading to lesions in axons. The diagnosis of MS is clinical, however, paraclinical tests are fundamental. In the laboratory study of cerebrospinal fluid and serum, the oligoclonal IgG bands (OCB IgG) analysis can evaluate intrathecal synthesis. We analyzed the prevalence of OCB IgG in MS and clinically isolated syndrome (CIS), the role of OCB IgG in the MS prognosis and CIS conversion, as well as its correlation with latitude effect. From 93 articles, 32 were used according to the inclusion criteria. The statistical analysis was made in the IBM SPSS version 23 software. The prevalence of OCB IgG in MS was $82,6 \%$ and in CIS $66,8 \%$. A non-linear correlation was observed between the prevalence of OCB IgG and the conversion from CIS to MS. No correlation was found between the presence of OCB IgG and MS prognosis. The main prevalence of OCB IgG was observed in the northern hemisphere, and at a latitude of $40^{\circ}$ or higher. The presence of OCB IgG in cerebrospinal fluid is connected to MS. OCB IgG positivity is linked to conversion from CIS to MS. This study was limited due to the small quantity of articles used in the prognosis analysis. There was not enough data to confirm the latitude effect.

Keywords: Multiple Sclerosis; Clinically Isolated Syndrome; OCB IgG; Prevalence; Prognosis

\section{Introduction}

The Multiple Sclerosis (MS) is an autoimmune and demyelinating inflammatory chronic disorder that, as it develops, gains a neurodegenerative capability. MS affects the central nervous system, being potentially the most common cause of neurologic deficiency in young adults [1]. It manifests itself by an inflammation of the CNS and by a deregulation of the immune system, leading to lesions in axons and therefore, damage of myelin along with axonal loss. The healing process of the inflamed axons forms multifocal sclerotic plaques that characterize the disease [1]. Different forms of presentation for MS have been identified. Relapsing remitting MS (RRMS) it's the most usual appearing in $85 \%$ of patients [2]. It consists in the occurrence of relapses, followed by total or partial recovery, the remission period. At this stage it's possible to provide the patient with complementary medication, reducing the severity of the relapse, regardless of the disease modifying therapy, aimed at the prevention of new relapses. MS affects twice as many women than men [1,2]. In about $65 \%$ [1] of patients with RRMS the disease develops into secondary progressive MS (SPMS), in which the clinical episodes become more frequent, leading to axonal degeneration and the possible presentation of signs of gliosis [2]. Primary progressive MS (PPMS) appears in 15\% [2] of the patients, consisting of the constant progression of the disease, without remission or relapses, resulting in increased disability faster than RRMS. Clinically isolated syndrome (CIS) is defined as the first clinical episode that presents characteristics that suggest a MS diagnosis. In these episodes the optical nerve, the brainstem and the spinal cord can be affected [3]. Approximately 85\% of patients develop MS from a CIS episode [4]. MS diagnosis is clinical, however, it is fundamental to use certain paraclinical tests $[5,6]$. The magnetic resonance imaging (MRI) allows the detection of lesions in the CNS, whereas the analysis 
of biological fluids, cerebrospinal fluid (CSF) and serum evaluates the presence or absence of oligoclonal IgG bands (OCB IgG). The search for oligoclonal IgG bands (OCB IgG), made in CSF and serum, allows the examination of existence of intrathecal inflammation. The intrathecal generation of immunoglobulins type IgG is done by clones of B lymphocytes, after exposure to unidentified antigens present in the CNS, this secretion generally remains throughout MS progression [2]. According with Thompson et al. [5], and after the 2017's McDonald criteria revision, these paraclinical tests are essential not only for a more immediate diagnosis but also for a differential diagnosis. Apart from the OCB IgG search, in the CSF analysis the absence of findings such as neutrophils, atypical cells or elevated protein concentration, allows to discard the presence of other diseases. In addition to the laboratorial tests, a simple brain MRI or in association with spinal cord MRI are recommended, once they can locate lesions and detect its dissemination in time, indicating if the lesions are active [5]. Once MS is diagnosed, an evaluation of the clinical state of the patient is made based on the Expanded Disability Status Scale (EDSS) [7]. EDSS was developed by Kurtzke, allowing the quantification of the disability based on clinical findings [8]. Through CSF and serum analysis, it is possible to assess the intrathecal presence of OCB IgG. Its importance comes from the $90 \%$ of MS cases that have presence of OCB IgG, even though this percentage can vary according to the geographic location of the patients $[1,9]$.

The standard technique for this detection is isoelectric focusing (IEF) on agarose gel followed by immunoblotting [10,11] or immunofixation $[12,13]$, allowing the immunoglobulin separation through the isoelectric point. IEF followed by immunoblotting has various advantages when compared with other electrophoresis variations, such as higher sensitivity, detection of a larger number of OCB IgG as well as an easier distinction and a more accurate interpretation [9]. According to Schwenkenbecher et al. [14]. OCB IgG sensitivity in MS patients is $98,5 \%$. This search is always done in CSF and serum simultaneously, since a positive result in both biologic fluids may exclude the possibility of a MS diagnosis [15]. The interpretation of the results is made though 5 different patterns of OCB IgG. Thus, the absence of OCB in CSF and serum indicates a negative pattern, type 1 . In type 2 the presence of two or more BOC restricted to CSF suggests CNS inflammation, due to intrathecal synthesis of IgG. This "positive" type 2 is the classical pattern observed in MS and CIS patients. The presence of OCB in both biologic fluids, but with a higher number in the CSF than in the serum, is classified as type 3 "higher than" and it indicates intrathecal IgG synthesis as well. In the "mirror" pattern, the presence of identical OCB is detected both in CSF and serum, it is labelled as type 4 and points to the presence of a systemic reaction. At last, type 5 shows the presence of monoclonal bands both in CSF and serum, and it can be related to monoclonal gammopathy $[9,10,12,16,17]$. It is important to have in mind that the OCB IgG presence is not specific to MS once OCB IgG can be detected in other inflammatory diseases, such as systemic lupus erythematosus or neurosarcoidosis [9]. Studies show that MS prevalence is higher in individuals originated from northern countries (Scandinavia and United Kingdom) and less common in tropical areas (Brazil, India and Saudi Arabia [18-20]. Genetic susceptibility and the surrounding environment are factors that can cause such prevalence $[2,18,20]$. The HLA-DRB1 gene was associated with a higher susceptibility to the disease while the Epstein-Barr virus has been shown to be involved in some cases of MS [2]. The prevalence of MS is higher in northern Europe and northern America countries ( $>30$ cases in 100000), average in south Europe, Australia and New Zealand (5 to 30 cases in 100000) and lower in Asia, South America and Africa $(<5$ cases in 100000) [21,22]. There is also the record of differences of OCB IgG detection in MS patients that can be related to latitude. There is a lower prevalence of OCB IgG in Asian countries, about $35 \%$ to $46 \%$, when compared to western countries, close to $90 \%$ $[9,23]$. Thus, in Scandinavia, United Kingdom and Canada more than $90 \%$ of patients have OCB IgG positivity and in south Europe (such as Portugal, Spain and Turkey) only between $81 \%$ to $87 \%$ are OCB IgG positive [24,25]. However, there are exceptions detected in Sardinia, for example, where there is a high prevalence of MS $(151,9$ cases in 100000$)[26,27]$. There are also some studies defending that the presence of OCB IgG in CIS patients is connected to a development into a MS diagnosis $[22,28]$. Regarding the MS prognosis, it is expected that patients with negative OCB IgG have a slower progression compared with positive OCB IgG patients $[9,29]$. This prognosis can be evaluated by measuring EDSS progression for a determined follow-up period. Although OCB IgG presence alone can't make a MS diagnosis, this analysis is important as a support to clinical diagnosis due to its common appearance in an initial stage of the disease. The present study aims for the clarification of positive OCB IgG prevalence in MS and CIS patients and their association with the disease prognosis and conversion to CIS, it is also intended to study the relation between latitude and MS and CIS patients.

\section{Material and Methods}

\section{Data Search}

EndNote software was used to search online articles through PubMed. For the search terms like "multiple sclerosis", "oligoclonal bands", "cerebrospinal fluid" and "clinically isolated syndrome" were used. After this initial research, the abstracts were analyzed to select the articles that were in accordance to the inclusion criteria.

\section{Inclusion Criteria}

The search was conditioned by pre-defined inclusion criteria in order to obtain a solid sample. These inclusion criteria include articles with a minimum sample of 10 patients. In cases that the same articles include MS and CIS patient groups, these groups must be defined, and the results must be presented separately. The same procedure applies to articles that study the prognosis, thus the patients with progressive forms of MS had to be divided (PPMS and SPMS). In order for the results to be consistent, only the articles 
in which the technique used was IEF followed by immunoblotting were selected. Most of the included articles were published after 2000 , however, the articles related to the understanding of the disease and technique are prior to 2000.

\section{Article Selection}

Of the 93 articles initially selected, 67 were entirely analyzed. This exclusion of articles was made based on information from the abstracts, permitting the discard of articles that did not contain relevant information for this analysis. From these 67 articles, 32 were selected to include in this study. Therefore, articles that used IEF followed by immunofixation $(n=12)$, that used electrophoresis with silver stain ( $\mathrm{n}=7$ ), articles which did not specify the technique used or that used different techniques in its patient population $(n=14)$ and articles that only selected patients with positive or negative OCB IgG $(n=2)$, were rejected (Figure 1). For the OCB IgG prevalence in MS examination 22 articles were used, as well as 13 others for the OCB IgG prevalence in CIS. Regarding the MS prognosis, 4 articles were analyzed, and for the evaluation of CIS to MS conversion 10 articles were used. For the analysis of the relationship between latitude and OCB IgG, 20 articles were resorted to for MS and 11 for CIS (Table 1). For the analysis of the latitude effect, the location of each study was found, and the latitude was then determined through Google Maps, which provided a value that was rounded up to the unit. Articles that had samples from more than one country were excluded, since it was not possible to clarify the location of each population.

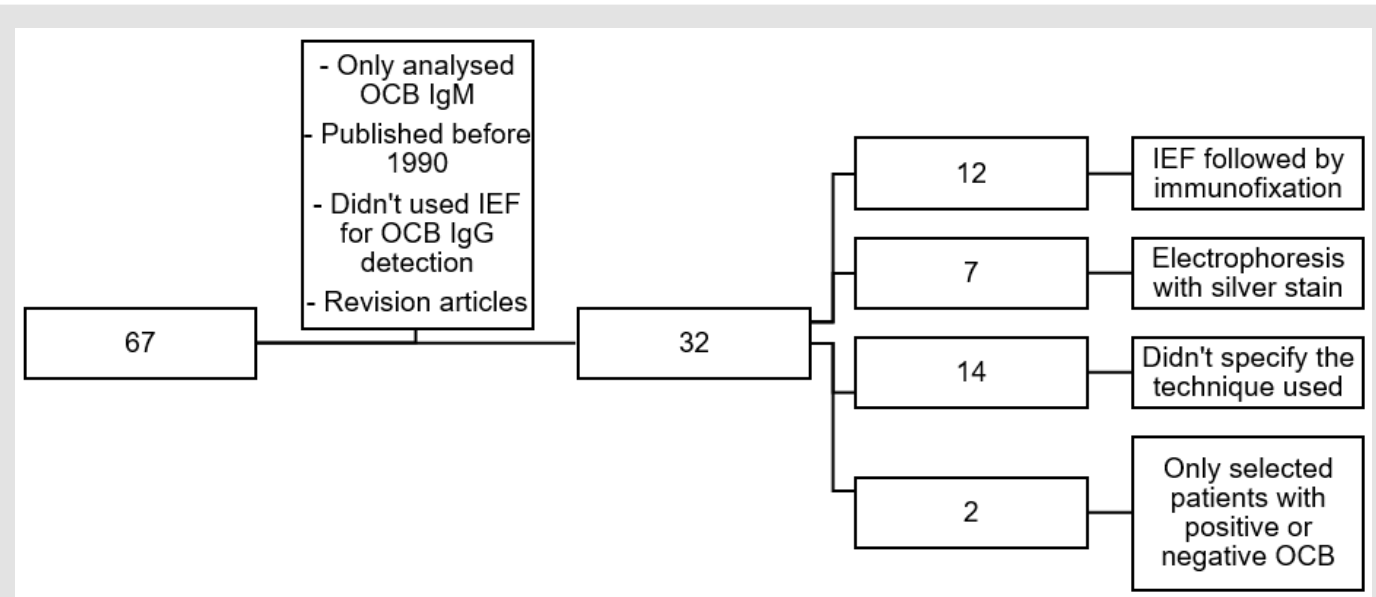

Figure 1: Article selection.

Table 1: Association of the 67 articles according to the inclusion criteria.

\begin{tabular}{|c|c|}
\hline \multicolumn{2}{|r|}{ Articles } \\
\hline OCB IgG prevalence in MS & $\begin{array}{l}\text { Frau J, et al. [30]; Becker M, et al. [31]; Lourenco P, et al. [32]; Rojas JI, et al. [33]; Caudie C, et al. [35]; Bourahouri A, et } \\
\text { al. [36]; Andlovic A, et al. [37]; Sa MJ, et al. [38]; Franciotta D, et al. [56]; Dujmovic I, et al. [57]; Sellebjerg F, et al. [58]; } \\
\text { Chang KH, et al. [59]; Gama PD, et al. [60]; Villar LM, et al. [61]; Caudie C, et al. [62]; Villar LM, et al. [63]; Presslauer S, } \\
\text { et al. [64]; Brandao C0, et al. [65]; Krakauer M, et al. [66]; da Gama PD, et al. [67]. }\end{array}$ \\
\hline OCB IgG prevalence in CIS & $\begin{array}{c}\text { Kuhle J, et al. [4]; Kinoshita M, et al. [22]; Tintore M, et al. [34]; Andlovic A, et al. [37]; Schwenkenbecher P, et al. [46]; } \\
\text { Masjuan J, et al. [47]; Gama PD, et al. [60]. }\end{array}$ \\
\hline MS prognosis & Frau J, et al. [30]; Becker M, et al. [31]; Lourenco P, et al. [32]; Rojas JI, et al. [33]. \\
\hline Conversion from CIS to EM & Kuhle J, et al. [4]; Kinoshita M, et al. [22]; Tintore M, et al. [34]; Schwenkenbecher P, et al. [46]; Masjuan J, et al. [47]. \\
\hline Effect of latitude in MS & $\begin{array}{l}\text { Frau J, et al. [30]; Becker M, et al. [31]; Lourenco P, et al. [32]; Rojas JI, et al. [33]; Caudie C, et al. [35]; Bourahouri A, et } \\
\text { al. [36]; Andlovic A, et al. [37]; Sa MJ, et al. [38]; Franciotta D, et al. [56]; Dujmovic I, et al. [57]; Sellebjerg F, et al. [58]; } \\
\text { Chang KH, et al. [59]; Gama PD, et al. [60]; Caudie C, et al. [62]; Villar LM, et al. [63]; Presslauer S, et al. [64]; Brandao } \\
\text { CO, et al. [65]; Krakauer M, et al. [66]; da Gama PD, et al. [67]. }\end{array}$ \\
\hline Effect of latitude in CIS & $\begin{array}{c}\text { Kinoshita M, et al. [22]; Tintore M, et al. [34]; Andlovic A, et al. [37]; Schwenkenbecher P, et al. [46]; Masjuan J, et al. } \\
\text { [47]; Gama PD, et al. [60]. }\end{array}$ \\
\hline
\end{tabular}

\section{Statistical Analysis}

The IBM SPSS version 23 software was used for statistical analysis. To evaluate the difference between OCB IgG prevalence in MS and CIS, t-Student for 2 independent samples test was used. Graphics were built to understand the relation between the variables. The results were presented as: mean \pm standard deviation and values of $\mathrm{p}<0.05$ were considered significant.

\section{Results}

Based on the analysis of the 32 articles, 8179 MS patients and 2460 CIS patients were studied. The ratio between the number of women and men is $2.28 \pm 0.36$, being that, in every article studied, the number of women is higher than men. The global mean age of the patients is $33 \pm 2.97$ years. 


\section{Prevalence of OCB IgG in MS and CIS}

OCB IgG prevalence in MS was $82.6 \%$ and in CIS was $66.8 \%$. Thus, the presence of OCB IgG in patients diagnosed with MS was shown to be superior when compared to patients with CIS ( $p=0,000$; $\varphi=10635$; $t=73.015$ ), with a mean difference of $15.8 \%$.

\section{Conversion from CIS to MS}

The articles studied take the clinical diagnosis of MS as conversion, which can be supported by MRI and laboratorial tests. A non-linear correlation between OCB IgG prevalence and conversion from CIS to MS was checked. From positive OCB IgG patients, $73.2 \%$ were converted to MS as compared to $25.1 \%$ with negative OCB IgG patients, during a follow-up of $50.4 \pm 8.7$ months. The conversion of CIS to clinically defined MS was related to the global mean age of each study. In positive OCB IgG, patients a conversion rate higher between 31 and 34 years old was observed, being that the study with a lower conversion rate was also the one that presents a lower mean age of 30 years old. In negative OCB IgG patients, the conversion rate is only higher than $40 \%$ in one of the studies with a mean age of 34 years old, no relation was verified between conversion and age of the patients.

\section{MS Prognosis}

One paper [30] from Sardinia analyzed the time the study group took to reach EDSS 3 and 6 during a mean follow-up time of 6 years. The prevalence of OCB IgG was 83.8\%. In this particular study, 95\% of patients had RRMS and the remaining had PPMS, being that $82.7 \%$ take DMT. After the follow-up, $24.85 \%$ reached EDSS 3 and $9.15 \%$ reached EDSS 6. Although no relation with statistical significance was found between these results and the presence or absence of OCB IgG, it was found between patients with a higher age onset and the presence of PPMS. Becker et al. [31] had as a purpose to observe the relation between the presence of OCB IgG and time to reach EDSS $4.87 \%$ of patients had positive OCB IgG and 85.7\% had RRMS and the remaining had PPMS. 34.9 $\%$ of patients reached EDSS 4 after follow-up. It wasn't found any relation between time to reach EDSS 4 and presence or absence of OCB IgG. Another investigation [32] analyzed disease progression through EDSS and disease ratio, as well as through the proportion of patients that reached EDSS 6 in 10 years into the disease. OCB IgG prevalence in this study was $72.5 \%$ and a higher presence of oligoclonal bands in patients with PPMS, when compared to RRMS and SPMS patients was observed. No association between presence or absence of OCB IgG and disease progression was confirmed. Lastly, a study by Rojas et al. [33] related OCB IgG presence with PPMS conversion to SPMS and with progression to an EDSS 6. The prevalence of oligoclonal bands was $90 \%$, and it was observed that there was a higher percentage of patients with positive OCB IgG (31\%) that reached EDSS 6 during follow-up, when compared to negative OCB IgG (10\%). Although with no statistical significance, it was also observed that more patients with positive OCB IgG converted to SPMS (33.5\%) compared to $15 \%$ of negative OCB IgG. This study concluded that OCB IgG presence is related with a worse prognosis.

\section{Effect of Latitude}

The articles included in this study were based on populations from diverse countries. Brazil and Argentina represent the southern hemisphere, and of the northern hemisphere, articles from Europe, Asia and north America were present, including the following countries: England, Germany, Denmark, Austria, Slovenia, Serbia, Czech Republic, France, Spain, Italy, Portugal, Japan, Taiwan and Canada. The higher prevalence of OCB IgG was found mostly in the northern hemisphere at a latitude higher than $40^{\circ}$ (Figure 2).

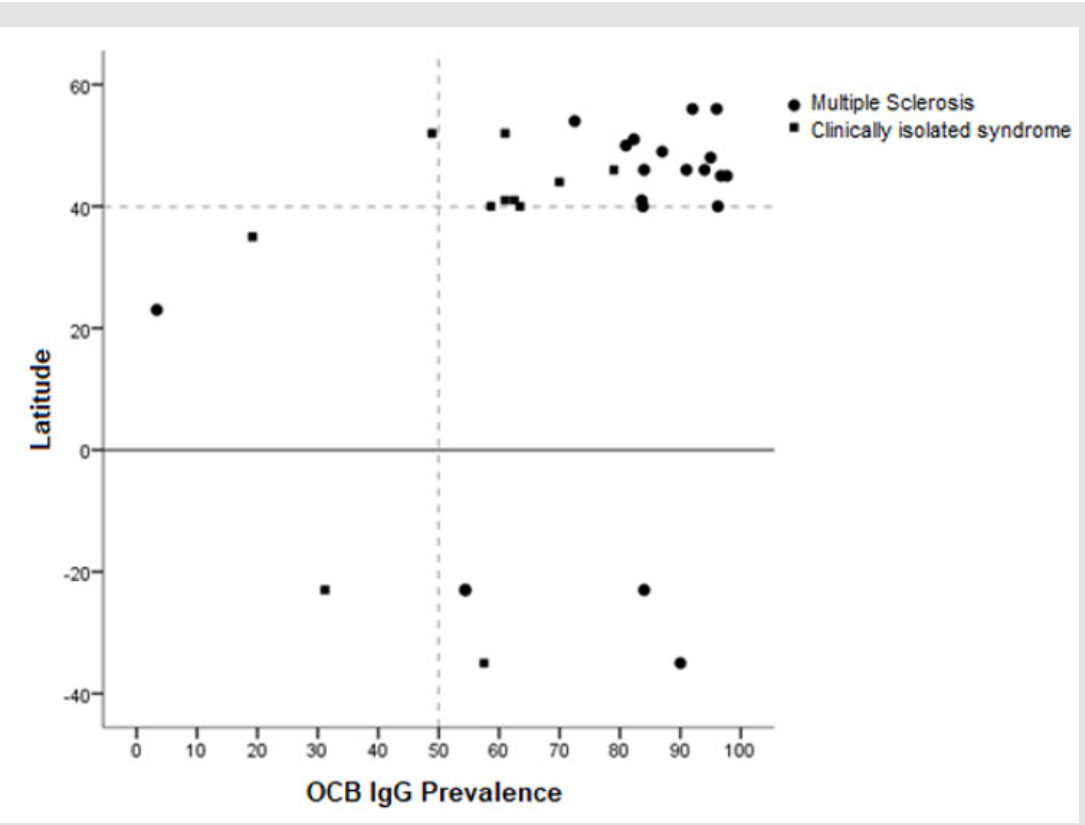

Figure 2: Effect of latitude and OCB IgG prevalence. 


\section{Discussion}

Although the presence of OCB IgG isn't by itself responsible for MS diagnosis, this analysis is important as a support to clinical diagnosis due to its common appearance in the initial stage of the disease. For this reason, studying the presence of OCB IgG is relevant in order to clarify its role and its clinical meaning for this disease. The articles used in this study present a population distribution with a higher number of women than men affected by MS and CIS [34,35], which meets previous investigations [1,2]. The global mean age was 33 years old, representing the majority of people that present signs of MS, which is within the range of 20 to 40 years old [1]. The global result of prevalence of OCB IgG in MS patients, in every study included, is of $82,6 \%[9,12,36,37]$. According to Sa et al. [38] this prevalence is similar to the results obtained by IEF followed by immunoblotting. However, in this study there are results from articles based on Asian populations, in which was found a smaller OCB IgG prevalence. Studies from Kikuchi et al. [39] and Siritho et al. [40] indicate that these populations commonly have a lower percentage of positive OBC IgG in MS patients. On the other side, Link et al. [9] indicates that the method used for OCB IgG search has an important role in prevalence, since the use of different techniques will have a lower sensitivity, thus making the result comparison unreliable. Regarding the negative OCB IgG patients, it is also possible for some to not have a correct MS diagnosis, since there is the hypothesis that other diseases, with similar MRI findings to MS, may be present [41]. Positive OCB IgG in CIS were associated to a higher risk of conversion to MS, since a larger risk related to band absence was shown. According to Tintoré et al. [34] OCB IgG presence is related to MS evolution, possibly being more relevant than visible MRI lesions since patients with a normal MRI and positive OCB IgG manifest higher risk of a second clinical episode, relatively to patients with a normal MRI but with negative OCB IgG. These signs can be important because, through OCB IgG search, the possibility of clinical MS diagnosis can be admitted while in the absence of OCB IgG, suggesting the presence of other diseases.

The percentage of conversion from CIS to MS can vary according to different studies, due to the follow-up period and to the use of different criteria for MS diagnosis [22]. Besides the OCB IgG presence, there are other variables studied while associating the conversion to MS in CIS patients, such as the number and type of lesions identified by MRI [42] and environmental factors, including elevated values of antibodies anti-virus Epstein-Barr and lower values of vitamin D [43,44]. Kuhle et al. [4] concludes that individuals with CIS with a higher conversion to MS risk present positive OCB IgG and an elevated lesion number in MRI. The same study also indicates that the patient age at disease onset is related with risk of conversion, having higher ages a lower probability of conversion [45]. Thus, mean age of patients with conversion to MS was 31 years old compared with the 33 years old of the patients that did not converted during follow-up. In this study it wasn't possible to present strong results regarding age and risk of conversion association, however the articles that report higher conversion percentage have a global mean age between 31 and 34 years old $[46,47]$. The meaning of OCB IgG presence regarding disease progression isn't unequivocal, since the studies carried in this field don't always have identical results. The literature studied uses different parameters, hindering result comparison, thus making a statistical analysis not possible. EDSS is used to verify the time that patients take, since disease onset, to reach a certain value in this scale. This allows the evaluation of the possible association between oligoclonal bands and a faster disease evolution. Besides EDSS, it is also possible to verify if patients initially diagnosed with RRMS progress to SPMS, a more aggressive form of the disease. Regarding PPMS the disease development is faster, since there isn't a remission period in this form of MS, so the presence of OCB IgG that, according to Lourenço et al. [32] is more elevated than in other MS types, may not be associated with disease progression. PPMS is generally acknowledged in patients with older ages when compared with RRMS [48]. Two of the articles studied, Frau et al. [30] and Becker et al. [31], conclude that patients with higher ages in disease onset are associated with a worse prognosis, since these individuals reached a higher EDSS value (3 and 4, respectively) in less time. Other studies [49,50] support this conjecture, while admitting that RRMS patients and older ages in disease onset manifest more susceptibility to a faster progression. Although women are more affected by the disease than men, according to Frau et al. [30] they have a less aggressive disease course, but bibliography that could support this conclusion was not found. On the contrary, Debouverie and collaborators [50] indicates that differences between women and men concerning disease progression were not found. Regarding OCB IgG Zeman et al. [29] and Stendahl Brodin et al. [51] defend that the absence of OCB IgG is related with a better MS prognosis. According to Lourenço et al. [32] OCB IgG positivity isn't associated with disease progression, however Joseph et al. [52] demonstrated that negative OCB IgG patients had a better prognosis by studying the time that took to reach EDSS levels 4 and 6. Rojas et al. [33] even concludes that OCB IgG presence is related to disease aggressiveness by considering conversion from RRMS to SPMS and progression to EDSS 6. It must be taken into consideration that some of these studies did not analyze every factor that can interfere in disease prognosis, such as the use of DMT that, by preventing new relapses, can delay disease progression. MS has its highest prevalence in the northern hemisphere, for that reason the included studies are mostly from that area. The reason for this phenomenon is unknown, however it's observed that according to an individual's location the disease manifestation can vary. Certain genetic and environmental factors are responsible for triggering MS onset. Compston et al. [18] admitted the existence of a relation between MS and alleles from major histocompatibility complex (MHC), being that this association is stronger in northern European populations. Therefore, the study of certain genetic characteristics becomes more relevant, such as the presence of HLA DRB1 complex 
alleles, that are proved to be related to disease development [53]. Regarding environmental factors, Marrie et al. [20] reflected over some studies that concluded that lower levels of ultraviolet radiation are associated with MS presence, which can explain the lower MS prevalence in tropical areas. There's also evidence of the regulatory effects that vitamin D has in the cells of the immune system, which may justify why individuals with lower levels of vitamin D are more associated to MS [54,55]. Besides these factors, one MS type was identified as more common in Asian countries, named optic-spinal [9], which may explain why OCB IgG prevalence in these regions is lower, since this type of the disease rarely presents positive OCB IgG [23]. In this study it wasn't possible to observe if the effect between latitude and OCB IgG prevalence is significative. Nevertheless, it was verified that the regions where OCB IgG prevalence was more elevated were Italy [56], Serbia [57] and Denmark [58], and the lower prevalence in Taiwan [59] and Brazil [60-74].

\section{Conclusion}

The presence of OCB IgG in CSF is associated with MS, being also an important support for the diagnosis of MS while in presence of CIS. Regarding association of OCB IgG with disease prognosis, it is considered that the present study was limited due to the reduced number of included articles. The papers used in evaluation of prognosis are more recent publications, which can show a growing realization of the importance of these essays. This suggests that OCB IgG search will be increasingly supportive to clinical practice and leading to a more directed therapeutic. It is considered that there is a need for more extensive investigations in time as well as more complete ones in the MS prognosis field. Regarding the effect of latitude, it was noted that there's some variation in OCB IgG prevalence according to geographic location, however it can be stated that, based on the articles analyzed, not enough information has been obtained to prove so.

\section{References}

1. Compston A, Coles A (2002) Multiple Sclerosis. Lancet 359(9313): 1221-1231

2. Hauser SL, Oksenberg JR (2006) The Neurobiology of Multiple Sclerosis: Genes, Inflammation, and Neurodegeneration. Neuron 52(1): 61-76.

3. Kohriyama T (2011) Clinically isolated syndrome: prognostic markers for conversion to multiple sclerosis and initiation of disease-modifying therapy. Clinical neurology 51(3): 179-187.

4. Kuhle J, Disanto G, Dobson R, Adiutori R, Bianchi L, et al. (2015) Conversion From Clinically Isolated Syndrome to Multiple Sclerosis: A Large Multicentre Study. Multiple Sclerosis 21(8): 1013-1024.

5. Thompson AJ, Banwell BL, Barkhof F, Carroll WM, Coetzee T, et al. (2018) Diagnosis of multiple sclerosis: 2017 revisions of the McDonald criteria. Lancet Neurology 17(2): 162-173.

6. Poser CM, Paty DW, Scheinberg L, McDonald WI, Davis FA, et al. (1983) New Diagnostic Criteria for Multiple Sclerosis: Guidelines for Research Protocols. Annals of neurology 13(3): 227-231.

7. Kurtzke JF (1983) Rating neurologic impairment in multiple sclerosis Neurology 33(11): 1444-1452.
8. Ontaneda D, Fox RJ (2015) Progressive Multiple Sclerosis. Current opinion in neurology 28(3): 237-243.

9. Link H, Huang YM (2006) Oligoclonal bands in multiple sclerosis cerebrospinal fluid: an update on methodology and clinical usefulness. Journal of neuroimmunology 180(1-2): 17-28.

10. Andersson M, Alvarezcermeno J, Bernardi G, Cogato I, Fredman P, et al. (1994) Cerebrospinal Fluid in the Diagnosis of Multiple Sclerosis: A Consensus Report. J Neurol Neurosur Psy 57(8): 897-902.

11. Keir G, Luxton RW, Thompson EJ (1990) Isoelectric focusing of cerebrospinal fluid immunoglobulin G: an annotated update. Annals of clinical biochemistry 27(Pt 5): 436-443.

12. Dobson R, Ramagopalan S, Davis A, Giovannoni G (2013) Cerebrospinal fluid oligoclonal bands in multiple sclerosis and clinically isolated syndromes: a meta-analysis of prevalence, prognosis and effect of latitude. Journal of neurology, neurosurgery, and psychiatry 84(8): 909914.

13. Walker RW, Keir G, Johnson MH, Thompson EJ (1983) A rapid method for detecting oligoclonal IgG in unconcentrated CSF, by agarose isoelectric focusing, transfer to cellulose nitrate and immunoperoxidase staining. Journal of neuroimmunology 4(2): 141-148.

14. Schwenkenbecher P, Sarikidi A, Wurster U, Bronzlik P, Suhs KW, et al. (2016) McDonald Criteria 2010 and 2005 Compared: Persistence of High Oligoclonal Band Prevalence Despite Almost Doubled Diagnostic Sensitivity. International journal of molecular sciences 17(9): 1592.

15. Sindic CJ, Van Antwerpen MP, Goffette S (2001) The intrathecal humoral immune response: laboratory analysis and clinical relevance. Clinical chemistry and laboratory medicine 39(4): 333-340.

16. Petzold A (2013) Intrathecal Oligoclonal IgG Synthesis in Multiple Sclerosis. Journal of neuroimmunology 262(1-2): 1-10.

17. Freedman MS, Thompson EJ, Deisenhammer F, Giovannoni G, Grimsley G, et al. (2005) Recommended Standard of Cerebrospinal Fluid Analysis in the Diagnosis of Multiple Sclerosis: A Consensus Statement. Archives of neurology 62(6): 865-870.

18. Compston A, Coles A (2008) Multiple sclerosis. Lancet 372(9648): 1502 1517.

19. Kurtzke JF (2000) Multiple Sclerosis in Time and Space--Geographic Clues to Cause. Journal of neurovirology 6(Suppl 2): 134-140.

20. Marrie RA (2004) Environmental Risk Factors in Multiple Sclerosis Aetiology. The Lancet Neurology 3(12): 709-718.

21. Koch Henriksen N, Sorensen PS (2010) The changing demographic pattern of multiple sclerosis epidemiology. The Lancet Neurology 9(5): 520-532.

22. Kinoshita M, Daifu M, Tanaka K, Tanaka M (2017) Prognostic Value of Oligoclonal IgG Bands in Japanese Clinically Isolated Syndrome Converting to Clinically Definite Multiple Sclerosis. Journal of neuroimmunology 307: 1-6.

23. Nakashima I, Fujihara K, Misu T, Fujimori J, Sato S, et al. (2002) A Comparative Study of Japanese Multiple Sclerosis Patients With and Without Oligoclonal IgG Bands. Multiple Sclerosis 8(6): 459-462.

24. Andreadou E, Chatzipanagiotou S, Constantinides VC, Rombos A Stamboulis E, et al. (2013) Prevalence of cerebrospinal fluid oligoclonal IgG bands in Greek patients with clinically isolated syndrome and multiple sclerosis. Clinical neurology and neurosurgery 115(10): 20942098.

25. Idiman E, Ozakbas S, Dogan Y, Kosehasanogullari G (2009) The significance of oligoclonal bands in multiple sclerosis: relevance of demographic and clinical features, and immunogenetic backgrounds. Journal of neuroimmunology 212(1-2): 121-124.

26. Rosati G (2001) The Prevalence of Multiple Sclerosis in the World: An Update. Neurological sciences 22(2): 117-139. 
27. Granieri E, Casetta I, Govoni V, Tola MR, Marchi D, et al. (2000) The increasing incidence and prevalence of MS in a Sardinian province. Neurology 55(6): 842-848.

28. Gelfand JM (2017) Risk of Multiple Sclerosis After a Clinically Isolated Syndrome: From Magnetic Resonance Imaging to Oligoclonal Bands to Activated T Cells. JAMA neurology 74(3): 262-263.

29. Zeman AZ, Kidd D, McLean BN, Kelly MA, Francis DA, et al. (1996) A study of oligoclonal band negative multiple sclerosis. Journal of neurology, neurosurgery, and psychiatry 60(1): 27-30.

30. Frau J, Villar LM, Sardu C, Secci MA, Schirru L, et al. (2018) Intrathecal Oligoclonal Bands Synthesis in Multiple Sclerosis: Is It Always a Prognostic Factor? Journal of neurology 265(2): 424-430.

31. Becker M, Latarche C, Roman E, Debouverie M, Malaplate Armand C, et al. (2015) No prognostic value of routine cerebrospinal fluid biomarkers in a population-based cohort of 407 multiple sclerosis patients. BMC neurology 15(79).

32. Lourenco P, Shirani A, Saeedi J, Oger J, Schreiber WE, et al. (2013) Oligoclonal bands and cerebrospinal fluid markers in multiple sclerosis: associations with disease course and progression. Multiple Sclerosis 19(5): 577-584.

33. Rojas JI, Tizio S, Patrucco L, Cristiano E (2012) Oligoclonal bands in multiple sclerosis patients: worse prognosis? Neurological research 34(9): 889-892.

34. Tintore M, Rovira A, Rio J, Tur C, Pelayo R, et al. (2008) Do Oligoclonal Bands Add Information to MRI in First Attacks of Multiple Sclerosis? Neurology 70(13 Pt 2): 1079-1083.

35. Caudie C, Allauzen O, Bancel J, Later R (2000) Role of Isoelectric Focusing of Cerebrospinal Fluid Immunoglobulin $G$ in the Early Biological Assessment of Multiple Sclerosis. Annales de biologie clinique 58(2): 187-193.

36. Bourahoui A, De Seze J, Guttierez R, Onraed B, Hennache B, et al. (2004) CSF Isoelectrofocusing in a Large Cohort of MS and Other Neurological Diseases. European journal of neurology 11(8): 525-529.

37. Andlovic A, Babic M, Accetto S, Rot U (2012) Comparison of Two Methods for the Detection of Oligoclonal Bands in a Large Number of Clinically Isolated Syndrome and Multiple Sclerosis Patients. Clinical neurology and neurosurgery 114(6): 659-662.

38. Sa MJ, Sequeira L, Rio ME, Thompson EJ (2005) Oligoclonal IgG Bands in the Cerebrospinal Fluid of Portuguese Patients With Multiple Sclerosis: Negative Results Indicate Benign Disease. Arq neuropsiquiatria 63(2B): 375-379.

39. Kikuchi S, Fukazawa T, Niino M, Yabe I, Miyagishi R, et al. (2003) HLArelated Subpopulations of MS in Japanese With and Without Oligoclonal IgG Bands. Human Leukocyte Antigen. Neurology 60(4): 647-651.

40. Siritho S, Prayoonwiwat N (2007) A Retrospective Study of Multiple Sclerosis in Siriraj Hospital, Bankok, Thailand. Can J Neurol Sci 34(1): 99-104.

41. Solomon AJ, Klein EP, Bourdette D (2012) “Undiagnosing” Multiple Sclerosis: The Challenge of Misdiagnosis in MS. Neurology 78(24): 19861991

42. Fisniku LK, Brex PA, Altmann DR, Miszkiel KA, Benton CE, et al. (2008) Disability and T2 MRI Lesions: A 20-year Follow-Up of Patients With Relapse Onset of Multiple Sclerosis. Brain 131(Pt 3): 808-817.

43. Lunemann JD, Tintore M, Messmer B, Strowig T, Rovira A, et al. (2010) Elevated Epstein-Barr Virus-Encoded Nuclear antigen-1 Immune Responses Predict Conversion to Multiple Sclerosis. Annals of neurology 67(2): 159-169.

44. Martinelli V, Dalla Costa G, Colombo B, Dalla Libera D, Rubinacci A, et al. (2014) Vitamin D Levels and Risk of Multiple Sclerosis in Patients With Clinically Isolated Syndromes. Multiple Sclerosis 20(2): 147-155.
45. Mowry EM, Pesic M, Grimes B, Deen SR, Bacchetti P, et al. (2009) Clinical predictors of early second event in patients with clinically isolated syndrome. Journal of neurology 256(7): 1061-1066.

46. Schwenkenbecher P, Sarikidi A, Bonig L, Wurster U, Bronzlik P, et al. (2017) Clinically Isolated Syndrome According to McDonald 2010: Intrathecal IgG Synthesis Still Predictive for Conversion to Multiple Sclerosis. International journal of molecular Sciences 18(10): 2061.

47. Masjuan J, Alvarez Cermeno JC, Garcia Barragan N, Diaz Sanchez M, Espino M, et al. (2006) Clinically isolated syndromes: a new oligoclonal band test accurately predicts conversion to MS. Neurology 66(4): 576578.

48. Ebers GC (2005) Journal of neurology 252(3): 15-20.

49. Binquet C, Quantin C, Le Teuff G, Pagliano JF, Abrahamowicz M, et al. (2006) The Prognostic Value of Initial Relapses on the Evolution of Disability in Patients With Relapsing-Remitting Multiple Sclerosis. Neuroepidemiology 27(1): 45-54.

50. Debouverie M, Pittion Vouyovitch S, Louis S, Guillemin F (2008) Natural History of Multiple Sclerosis in a Population-Based Cohort. European journal of neurology 15(9): 916-921.

51. Stendahl Brodin L, Link H (1980) Relation Between Benign Course of Multiple Sclerosis and Low-Grade Humoral Immune Response in Cerebrospinal Fluid. Journal of neurology, neurosurgery, and psychiatry 43(2): 102-105.

52. Joseph FG, Hirst CL, Pickersgill TP, Ben Shlomo Y, Robertson NP, et al. (2009) CSF Oligoclonal Band Status Informs Prognosis in Multiple Sclerosis: A Case Control Study of 100 Patients. Journal of neurology, neurosurgery, and psychiatry 80(3): 292-296.

53. Balnyte R, Rastenyte D, Vaitkus A, Skrodeniene E, Vitkauskiene A, et al. (2016) Associations of HLA DRB1 Alleles With IgG Oligoclonal Bands and Their Influence on Multiple Sclerosis Course and Disability Status. Medicina (Kaunas) 52(4): 217-222.

54. Kamen DL, Tangpricha V (2010) Vitamin D and molecular actions on the immune system: modulation of innate and autoimmunity. J Mol Med (Berl) 88(5): 441-450.

55. Simon KC, Munger KL, Ascherio A (2012) Vitamin D and multiple sclerosis: epidemiology, immunology, and genetics. Current opinion in neurology 25(3): 246-251.

56. Franciotta D, Di Stefano AL, Jarius S, Zardini E, Tavazzi E, et al. (2011) Cerebrospinal BAFF and Epstein-Barr Virus-Specific Oligoclonal Bands in Multiple Sclerosis and Other Inflammatory Demyelinating Neurological Diseases. Journal of neuroimmunology 230(1-2): 160-163.

57. Dujmovic I, Mesaros S, Pekmezovic T, Levic Z, Drulovic J (2004) Primary Progressive Multiple Sclerosis: Clinical and Paraclinical Characteristics With Application of the New Diagnostic Criteria. European journal of neurology 11(7): 439-444.

58. Sellebjerg F, Jensen CV, Christiansen M (2000) Intrathecal IgG Synthesis and Autoantibody-Secreting Cells in Multiple Sclerosis. Journal of neuroimmunology 108(1-2): 207-215.

59. Chang KH, Lyu RK, Chen CM, Hsu WC, Wu YR, et al. (2006) Clinical Characteristics of Multiple Sclerosis in Taiwan: A Cross-Sectional Study. Multiple Sclerosis 12(4): 501-506.

60. Gama PD, Machado Ldos R, Livramento JA, Gomes HR, Adoni T, et al. (2009) Study of oligoclonal bands restricted to the cerebrospinal fluid in multiple sclerosis patients in the city of São Paulo. Arquivos de neuropsiquiatria 67(4): 1017-1022.

61. Villar LM, Masterman T, Casanova B, Gomez Rial J, Espino M, et al. (2009) CSF oligoclonal band patterns reveal disease heterogeneity in multiple sclerosis. Journal of neuroimmunology 211(1-2): 101-104. 
62. Caudie C, Birouk AM, Bancel J, Claudy D, Gignoux L, et al. (2005) Cytoimmunological profile of cerebrospinal fluid in diagnosis of multiple sclerosis. Pathologie-biologie 53(2): 68-74.

63. Villar LM, Masjuan J, Sadaba MC, Gonzalez Porque P, Plaza J, et al. (2005) Early Differential Diagnosis of Multiple Sclerosis Using a New Oligoclonal Band Test. Archives of neurology 62(4): 574-577.

64. Presslauer S, Milosavljevic D, Brucke T, Bayer P, Hubl W (2008) Elevated levels of kappa free light chains in CSF support the diagnosis of multiple sclerosis. Journal of neurology 255(10): 1508-1514.

65. Brandao CO, Ruocco HH, Farias AS, Oliveira C, Cendes F, et al. (2006) Intrathecal Immunoglobulin G Synthesis and Brain Injury by Quantitative MRI in Multiple Sclerosis. Neuroimmunomodulation 13(2): 89-95.

66. Krakauer M, Schaldemose Nielsen H, Jensen J, Sellebjerg F (1998) Intrathecal Synthesis of Free Immunoglobulin Light Chains in Multiple Sclerosis. Acta neurologica Scandinavica 98(3): 161-165.

67. Da Gama PD, Machado Ldos R, Livramento JA, Gomes HR, Adoni T, et al (2015) Oligoclonal Bands in Cerebrospinal Fluid of Black Patients With Multiple Sclerosis. BioMed research international 2015: 217961.

68. Bednarova J, Stourac P, Adam P (2005) Relevance of Immunological Variables in Neuroborreliosis and Multiple Sclerosis. Acta neurologica Scandinavica 112(2): 97-102.

ISSN: 2574-1241

DOI: 10.26717/BJSTR.2020.28.004611

Ana Valado. Biomed J Sci \& Tech Res

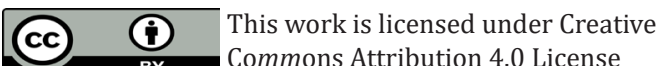

Submission Link: https://biomedres.us/submit-manuscript.php
69. Lechner Scott J, Spencer B, De Malmanche T, Attia J, Fitzgerald M, et al. (2012) The Frequency of CSF Oligoclonal Banding in Multiple Sclerosis Increases With Latitude. Multiple Sclerosis 18(7): 974-982.

70. Villar LM, Garcia Barragan N, Sadaba MC, Espino M, Gomez Rial J, et al. (2008) Accuracy of CSF and MRI criteria for dissemination in space in the diagnosis of multiple sclerosis. Journal of the neurological sciences 266(1-2): 34-37.

71. Tintore M, Rovira A, Brieva L, Grive E, Jardi R, et al. (2001) Isolated Demyelinating Syndromes: Comparison of CSF Oligoclonal Bands and Different MR Imaging Criteria to Predict Conversion to CDMS. Multiple Sclerosis 7(6): 359-363.

72. Rojas JI, Patrucco L, Edgardo C (2010) Oligoclonal Bands and MRI in Clinically Isolated Syndromes: Predicting Conversion Time to Multiple Sclerosis. Journal of neurology 257(7): 1188-1191.

73. Zipoli V, Hakiki B, Portaccio E, Lolli F, Siracusa G, et al. (2009) The Contribution of Cerebrospinal Fluid Oligoclonal Bands to the Early Diagnosis of Multiple Sclerosis. Multiple Sclerosis 15(4): 472-478.

74. Sharief MK, Thompson EJ (1991) The predictive value of intrathecal immunoglobulin synthesis and magnetic resonance imaging in acute isolated syndromes for subsequent development of multiple sclerosis. Annals of neurology 29(2): 147-151.

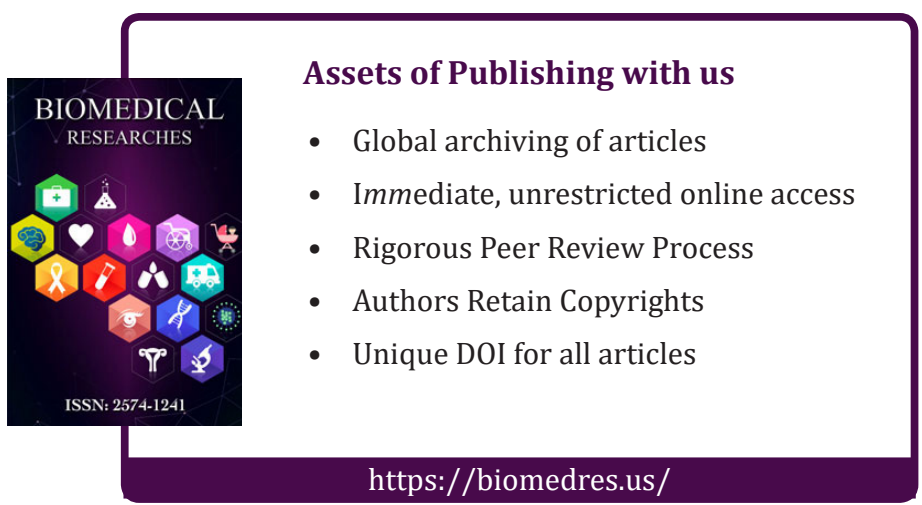

